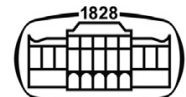

AKADÉMIAI KIADÓ

\title{
An inventory to the requalification of the Ex European city in Biskra
}

\author{
Hiba Barbara $^{1 *}$ (๑) and Tamás Molnár ${ }^{2}$
}

\section{Pollack Periodica • \\ An International Journal \\ for Engineering and Information Sciences}

16 (2021) 2, 170-175

DOI:

$10.1556 / 606.2020 .00232$

(c) 2020 The Author(s)

\section{ORIGINAL RESEARCH PAPER}

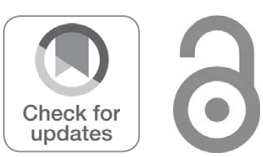

*Corresponding author. E-mail: barbara.hiba6@gmail.com

\author{
${ }^{1}$ Marcel Breuer Doctoral School, Faculty of Engineering and Information Technology, University of \\ Pécs, Boszorkány u. 2, H-7624 Pécs, Hungary \\ ${ }^{2}$ Department of Visual Studies, Faculty of Engineering and Information Technology, University of \\ Pécs, Boszorkány u. 2, H-7624 Pécs, Hungary
}

Received: May 5, 2020 • Revised manuscript received: September 4, 2020 • Accepted: September 21, 2020 Published online: April 27, 2021

\begin{abstract}
The urban story of the Ex European city in Biskra presents an inevitable impact on the perceptive images of the Algerian cities. The examination of the building's condition in the historical center indicates a deteriorated state in most of the structure caused by various degradations. The field study aims to classify the French quarter's constructions according to multiple criteria, based on the identifications of related conservation statuses. Thus the census data contributes to the regeneration of the checkerboard condition while proceeding with the resolution of the threatening mutations - amplifying the qualities and potentials for a sustainable renewal of this built heritage.
\end{abstract}

\section{KEYWORDS}

urban heritage, French check-board, requalification, city identity

\section{INTRODUCTION}

"A city is more than a place in space; it is a drama in time" wrote Patrick Geddes [1]. The scenes, the events and memories framed in a particular place through different periods, hence synchronize to construe the meanings and the values of each line in the city [2]. The urban heritage is the essential dimension to the recognition of the tangible and intangible features of the space; it considers the importance of the surrounding environment based on the perspectives of the built heritage, which determines the sensibility for multiple experiences, and the shaping of people's identities in their urban landscapes $[3,4]$. The hierarchy of the urban images in Algeria today is defined by the evolution of various qualities, including the logical compositions of past influences and cultural diversities. The French city's inherited remains and the planning of the so-called colonial checkerboard in Biskra introduce a particular thinking. With the design of series of monuments; hotels; and public spaces; and other interesting equipment; the urban center responds perfectly to the needs of the users, providing the unique Saharan experience in the city of Biskra: "The gate of the desert" [5-7].

Nonetheless, an increasing number of French cultural and historical properties are today at risk, against a small interest for action and development plans from the responsible authorities, which creates the first motivation for the subsequent field investigation. The study presents a detailed classification for the current condition in the colonial checkerboard of Biskra. The visit of the site, the reviews on the outdoors and the exterior envelopes with the structural and esthetic circumstances of the constructions formulates the support for the data collection process. The resolution and the enhancement of different types of degradations and problems, is an intermediate link between the amplification of the ephemeral qualities presented in the site and the opportunities for upgrading its situation and elaborating solid planning. Along with these steps the paper is mainly structured to connect three dependent concepts (Fig. 1): recognizing the qualities, the analysis of the problems, and the interpretation of the potentials. 


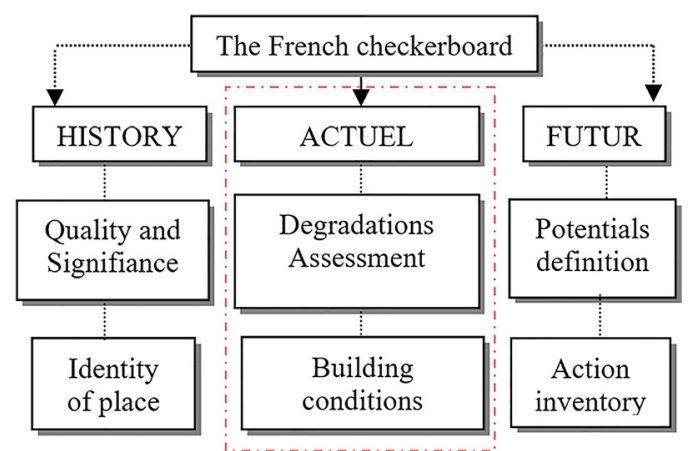

Fig. 1. Conceptual framework: towards the requalification of the Ex European city in Biskra

(Source: Author)

Thus the diagnosis of the degradations on the urban and the architectural scales is the vital interest of the research project. The work's multidisciplinary opens the doors to understanding the French-built heritage and the importance of approaching the issues around its perception and integration.

\section{BACKGROUND OF THE STUDY AREA}

The oasis of the Ziban presents the first glimpse of the grand Sahara of Algeria. With a unique character and a vernacular outlook, the Saharan Kasbah of the old Biskra reflects the typical local planning of the region's traditional settlements. With the French arrival, the alignment project in the Northern side of the old oasis proceeded an orthogonal grid planning for a European quarter, introduced with a distinct regularity, and urban variation when sighted with the general local structure of Biskra [6, 7].

The urban development of the colonial Checkerboard enclosed the qualities of the ultimate European plan, with organized repartition of the equipment responding to the needs of the city and its occupants, and reflecting the significance of its built heritage. The city of Biskra today is witnessing an interesting rate when it comes to urban growth. This phenomenon is directly affecting the qualities of the French historical center that is suffering from severe and advanced debilitations affecting the stability and permanence of its built heritage. The Market place remains the living core of the site; the rest of the structure lacks the same vitality and became gradually neglected and enclosed compared to the city's expansion towards the peripheries in favor of modern settlements $[8,9]$. The research project's objective is to create a detailed classification of the site's constructions according to multiple criteria. The inventory on the different blocks is the key to generating the recent situation and diagnosing the building's condition, working towards revitalizing the Checkerboard quarter.

\section{METHOD AND FIELD STUDY PROCESS}

In order to approach the aims of the research, the site has been visited continuously; the initial observations were followed by taking multiple photos, sketches, videos and notes. The comparison and analysis of ancient documents and historical plans were also a fundamental base to conclude the stratification and the site's modifications as well as the past narratives and descriptions mentioning the colonial Checkerboard and its emergence. As follows, the choice of the study area is based on the outlining of the European quarter's historical implantations. The center's evolution suggests that the site responds to the logical order of three successive phases [9]. The first starts from the south of "Saint Germain" fort and the old core of the village "Ras Elma", respectively; the next two dispositions follow the existing structure's axes in a coherent urban composition. The study zone delimitation was narrowed to the last two implantations as it represents no visible link with the local urban planning. While the first disposition still shares the connection with the local village, the chosen area seems to reflect the French planning's the perfect regularity in the old Biskra (Fig. 2).

\subsection{Definition of the research criterions}

The first step in this investigation process starts with the division of the study area into several blocks (Fig. 3). As follows, each block is coded according to its related series

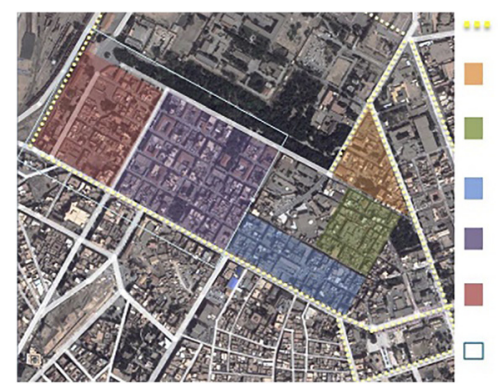

Delimitation of the site

The old village Ras el Ma

The Market place

The First implantation

The Second implantation

The Third implantation

The Study area

Fig. 2. The Plan of the Checkerboard

(Source: Google maps treated by the author)

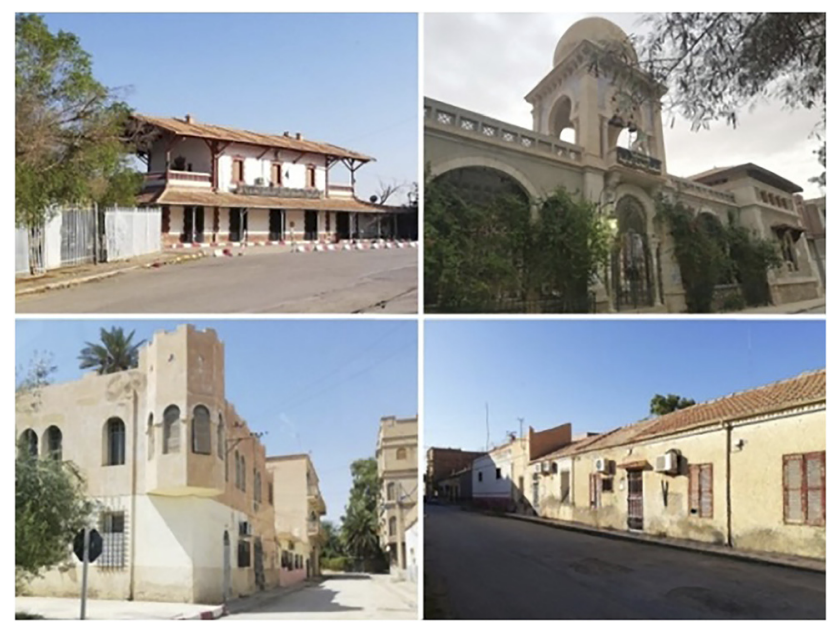

Fig. 3. Overview on some constructions in the site (Source: Author) 
Table 1. Coding and definition of the research criteria

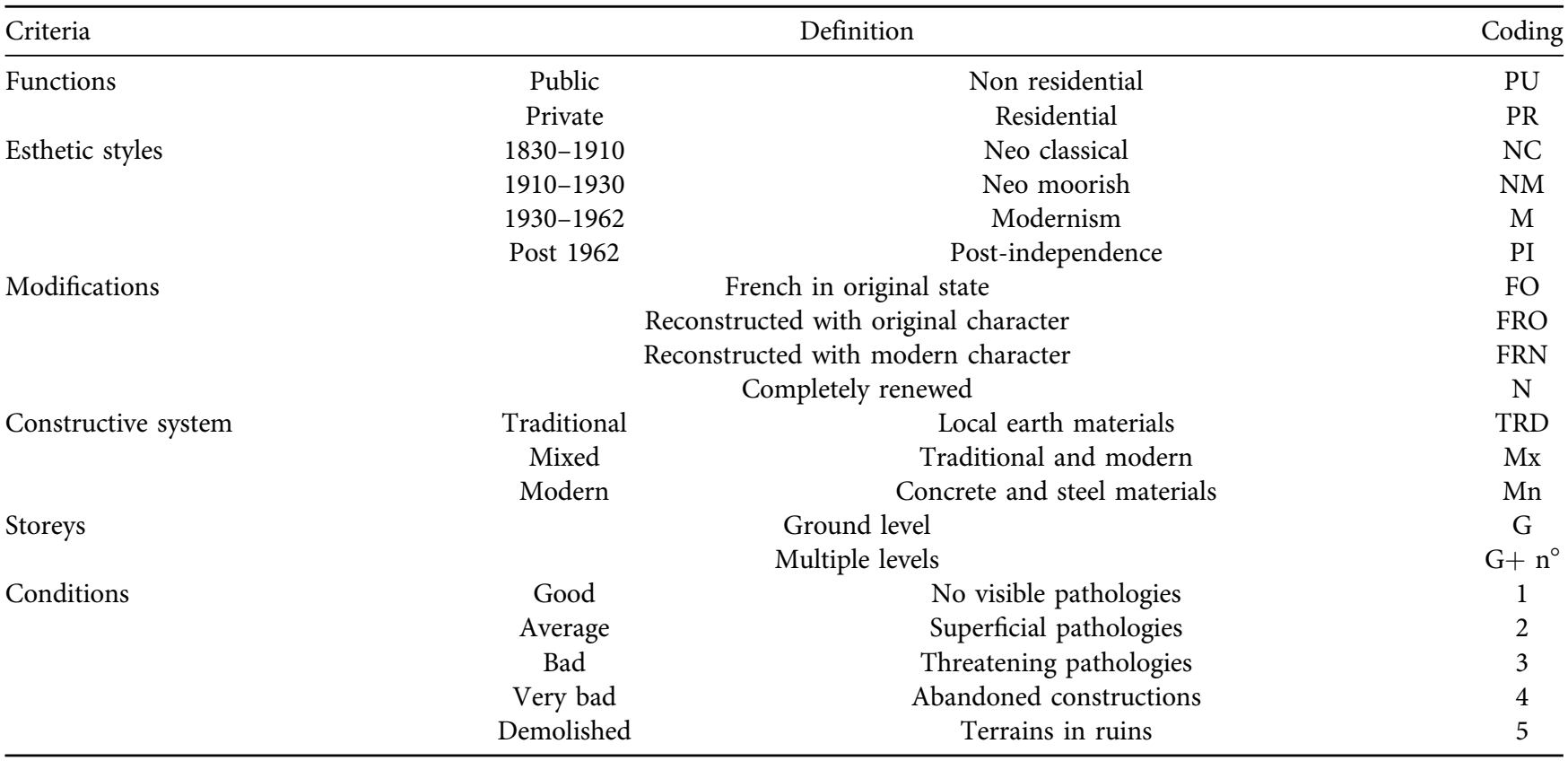

of constructions; subsequently the assessment was applied to 273 plots occupying 46 blocks. The assignment of pertinent criteria for each building in different neighborhoods regroups the cases into relevant categories and conditions, setting up the site's composing units. For facilitating the inquiry process, the collected data was abbreviated into codes defining the criteria of the study (Table 1).

3.1.1. The functions of the buildings. A dense residential fabric takes over most of the site, however important distributions are introduced in several blocks presenting more or less valuable monuments. Newly added activities; mostly commercial are present in the Checkerboard, in forms of different stores in the Neo-classical arcades characterizing the site's urban façades.

3.1.2. The esthetic styles. The historical emergence of the French styles, introduces a variety of designs when it comes to the ornamentations and the aesthetics of the buildings [6, 7] (Fig. 3). The approach adapts the post-revolution style for most of the constructions known with the Neo-classical and the Neo-Moorish design styles, mostly used in the larger scale constructions that require attractive exteriors and façades, and other details of private residences. Some examples of the Eclecticism style, especially in the former city hall's features, construct one of the crucial landmarks in the Checkerboard.

3.1.3. The stratification, evolution and modifications. Even though the colonial Checkerboard appears to be in the original form of its first planning, the constructions have known multiple changes and modifications. Three main elements stratify the buildings' changes: First, the actions of time and climate; figuring in the rapid aging of the constructions. Second, the modern additions and the introduction of new materials to the original units. Third, the neglecting and the abandonment of other groups for various reasons, either related to the regional development plans or the habitant's personal choices.

3.1.4. The constructive system. The use of the materials available in the site is the main logic of the local auto constructed system, which vastly influenced the French adaptations in the Checkerboard. Earth materials, local clays bricks dried in the sun, and stones of the river, all form the face of the traditional constructive system $[5,8]$. A radical change was known after introducing modern materials, including concrete and steel. However, the French's layout homogeneity does not separate from the recognition of its modifications and the use of these construction systems. The meeting of a moderate logic of local designs and modern regularity is the essential thinking behind the planning of the Checkerboard in the Sahara's low regions.

3.1.5. The number of storeys. Historically speaking, the Checkerboard creation generates ground floor planning and one level building for the private residences [8]. For public units, certain monumentality is given to the design, among the decorative style's choice and the overall appearance of the urban façades. Nonetheless, the post-independence buildings present the high residential units that can reach more than four levels, which eventually impacts the harmony of the different blocks and the typology of its constructions.

3.1.6. The condition of the buildings. The analysis approach is based on the previous criterion and represents the most critical phase of this study. The definition of the condition states is followed by the logical sequencing of 
Table 2. Evaluation sheet and data collection of Block $\mathrm{N}^{\circ} 9$ : classification and building conditions

\begin{tabular}{|c|c|c|c|c|c|c|c|c|c|c|}
\hline \multirow[b]{2}{*}{ Block $n^{\circ}$} & \multirow[b]{2}{*}{ Function } & \multirow[b]{2}{*}{ Esthetic Style } & \multirow[b]{2}{*}{ Modifications } & \multirow[b]{2}{*}{ Constructive system } & \multirow[b]{2}{*}{ Story } & \multicolumn{5}{|c|}{ Condition } \\
\hline & & & & & & 1 & 2 & 3 & 4 & 5 \\
\hline A9 & $\mathrm{PR}$ & PI & $\mathrm{N}$ & $\mathrm{Mn}$ & $\mathrm{G}+2$ & 0 & & & & \\
\hline B9 & PR & $\mathrm{NC}$ & $\mathrm{FO}$ & Trd & G & & & ○ & & \\
\hline C9 & PR & NC & FO & Trd & $\mathrm{G}$ & & & 0 & & \\
\hline D9 & $\mathrm{PR}$ & NC & $\mathrm{FO}$ & Trd & G & & & - & & \\
\hline E9 & PR & PI- NC & FRM & $\mathrm{Mx}$ & $\mathrm{G}+1$ & & 0 & & & \\
\hline F9 & PR & NC & FO & Trd & $\mathrm{G}+1$ & & & 0 & & \\
\hline G9 & $\mathrm{PR}$ & NC & $\mathrm{FO}$ & Trd & G & & & & 0 & \\
\hline $\mathrm{H} 9$ & $\mathrm{PR}$ & PI & FRM & $\mathrm{Mx}$ & G & & 0 & & & \\
\hline I9 & $\mathrm{PR}$ & PI & FRM & $\mathrm{Mx}$ & G & & 0 & & & \\
\hline J9 & PR & PI & $\mathrm{N}$ & $\mathrm{Mn}$ & $\mathrm{G}+1$ & 0 & & & & \\
\hline K9 & PU & $\mathrm{NM}$ & $\mathrm{FO}$ & $\operatorname{Trd}$ & $\mathrm{G}+2$ & & 0 & & & \\
\hline L9 & PR & $\mathrm{NC}$ & FO & TRD & G & & & 0 & & \\
\hline
\end{tabular}

different types of buildings. The esthetic of the façades and its visual appearance along to the building's structural functioning are crucial elements to assessing the general harmony with the surrounding environment and the diagnosis of the physical and humid pathologies. Respectively, a scale from 1 to 5 was defined, where 5 represents the worst state of conservation, and the total abandonment of the built space. The logic description of each situation was constituted as follows:

1: Good, 2: Average, 3: Bad, 4: Very bad 5: demolished/in ruins.

Table 2 shows an example of the inventory sheet and the analysis method on one of the blocks (Block N9) (Fig. 3).

\section{THE INITIAL RESULTS OF THE STUDY}

The essential findings of the assessment and the diagnosis phase (Fig. 4) were directly conducted by the criteria of the research, revealing the global condition of the French Checkerboard. The modern innovations of the constructions; resume an influential time-lapse for architectural and urban mutations in the site. As stated in the preliminary observations on the 46 blocks; the majority of the built heritage in the center is in an extreme state of disrepair, while there are an important number of valuable monuments; some are standing in a moderate state against a lot more that are in danger; neglected and called for action. Three general categories were classified during the study, regrouping the total of the evaluated constructions:

A. French buildings in the original state;

B. French buildings in a reconstructed state, two subcategories were defined:

B.1. Reconstructed state, where most parts are remaining French (French character);

B.2. Reconstructed state, where most parts are renewed (modern character);

C. Post independent buildings in a new state.
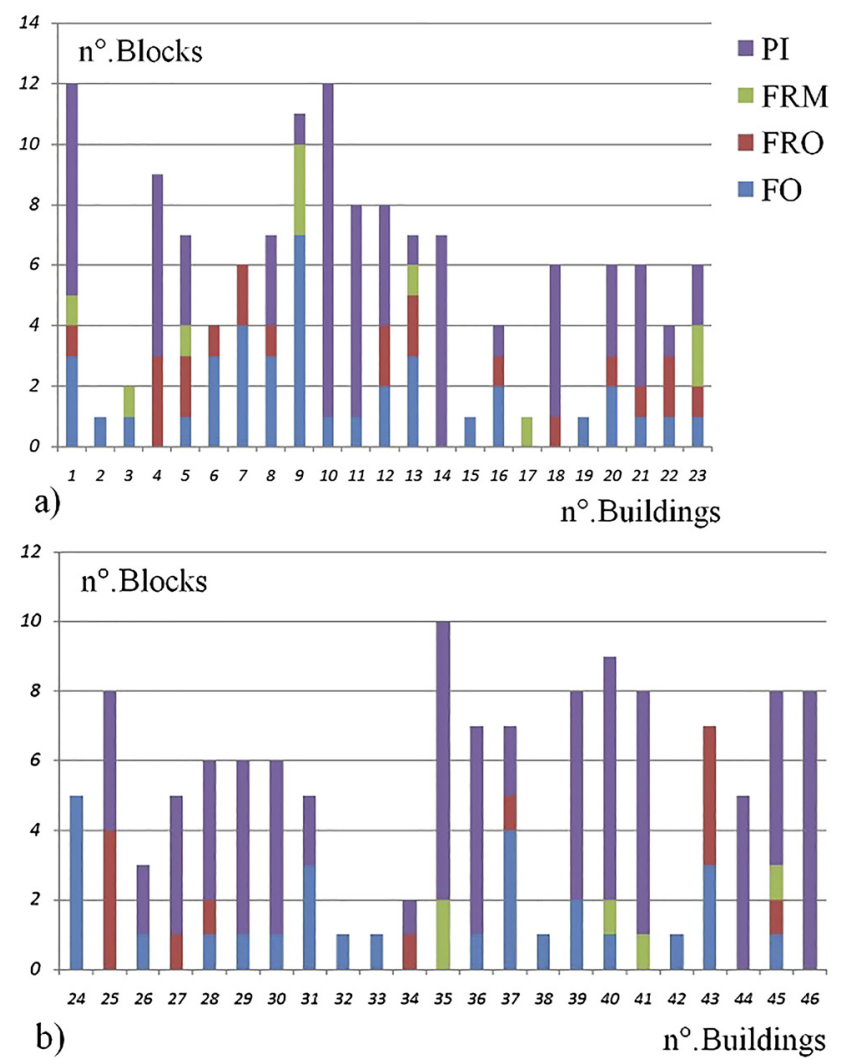

Fig. 4. Classification of the buildings in the site: a) Blocks 1 to 23; b) Blocks 24 to 46

\subsection{Building classification}

The interpretation of the results in the data collection phase indicates the analysis of 273 plots. However, ten terrains are found demolished or in ruins, decreasing the built space's total to 263 constructions, 147 of which are entirely renewed in the post-colonial periods, with modern architectural style, 49 properties are partially reconstructed, where 34 buildings preserve a French character; 15 are rebuilt with a contemporary styles, but still indicate the effects of the French design. Lastly, 67 constructions stand in the original 
Table 3. The state of conservation in the Colonial check board

\begin{tabular}{lccrrrc}
\hline Condition & Good & Average & Bad & bad & Total & Percentage \\
\hline F.O & 1 & 11 & 45 & 10 & 67 & $24.54 \%$ \\
F.R.O & 1 & 23 & 6 & 4 & 34 & $12.45 \%$ \\
F.R.M & 3 & 11 & 1 & $/$ & 15 & $5.49 \%$ \\
Total & 5 & 45 & 52 & 15 & 273 & $100 \%$ \\
\hline
\end{tabular}

French state, with minor changes in the authentic architectural and structural systems.

\subsection{The state of conservation}

According to the assessment scale of the building conditions, 11 of the original French construction are considered in an average state; 45 are classified in bad condition, whereas ten more are in an endangered status; either by the severe collapse of the load-bearing elements or the total abandonment of the units. The results on the reconstructed buildings of a modern character cover 11 properties; moreover 23 reconstructed buildings conserving an authentic style are classified between the average and the bad state, rarely a good condition (Table 3). Contrarily to the post-independent constructions that reflect (54\%) of a good condition. Very few public monuments and French buildings are classified in a valuable state.

\section{THE INTERPRETATION OF THE RESULTS}

The previous investigations on the French Checkerboard have mentioned the conditions of the buildings in the past years. The initial study of 1998, covering the French-built state, implies that in a total of $71.6 \%$ of the colonial cases, $65 \%$ are in good condition [8]. Moreover, according to the 2001 survey, applied on the first implantation of the site, including the historic core of the village Ras Elma, indicates that on $62 \%$ of the colonial buildings; most cases are found between good and average conditions, whereas $38 \%$ of the constructions return to the post-colonial period [9]. The interest of the present research project indicates the decline of the status of the French buildings and the advanced issues affecting the historical center. The original findings validate the continuous degradations; thus, the rate of renewal and reconstructions in the modern period has rapidly increased. The private residences create a problematic state when most original constructions are in a very bad condition; the wellshaped buildings are taking over significant parts of the Checkerboard. The use of high story buildings is the modern approach in the urban center that presents a contradiction to the single story buildings known in the French period, which profoundly influences the authenticity; the harmony and the urban image of the Ex European city in Biskra.

On the micro-level, the architectural envelope analysis affirms that deteriorations are encountering the bad condition of the buildings. A generation of the alterations resumes the leading causes of the degradation, where the majority of the structure suffers from the effects of humid deteriorations, caused by infiltrations from the terrain; many

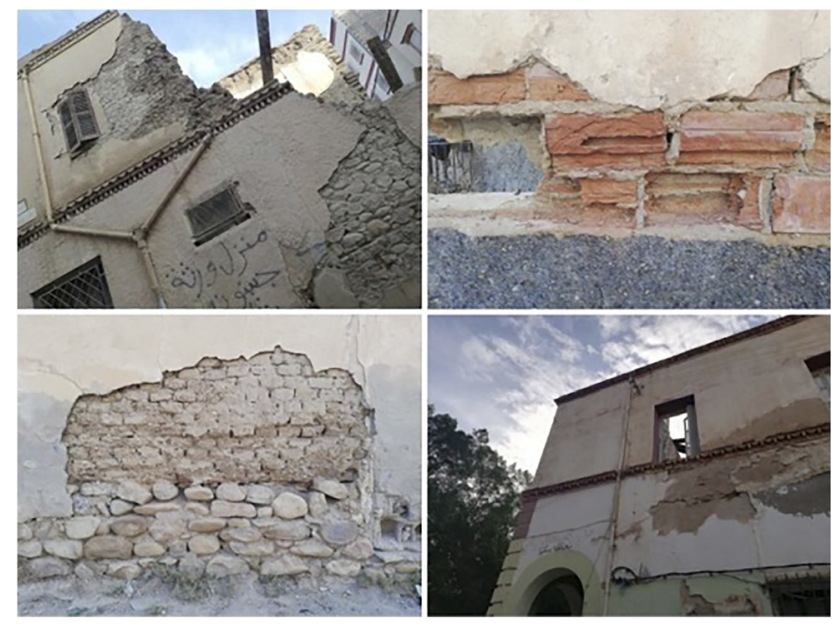

Fig. 5. Major problems affecting the construction materials (Source: Author)

parts sustain superficial and deep cracks, which affect the structural system and the foundations; threatening the stability of the constructions. In general, the same types of pathologies were repetitive and revealed during the study (Fig. 5), including: physical pathologies: from different types of cracking, to the collapse of the old parts, along with the crumbling of earth material and the detachment of the mortar. Moreover, the humid pathologies: presented with water infiltrations, condensations, humidity stains, and capillary effect are the essential issue of the terrain, and is probably justified with the historical disposition of the Checkerboard along the Seguias channels [8], presenting the dangerous effect of water on the traditional system using earth as the primary material of construction.

On a macro level, the urban issues are the conclusion for many problems at the site. The degradation of the built environment is added up to the devaluation of the public spaces, the streetscapes and the urban structuring units. The non-supportable streets and the increase of car use, in addition to the insufficiency of the parking spots, has a negative impact on the pedestrian experience and the user's perception of the significance and qualities of the historical center, the attention towards this issues is highly recommended to preserve the values of the place and guide its future development $[9,10]$. The modern refurbishments of the colonial center create a contradictory state compared to the original French constructions. Even though it seems to be in good condition, the unplanned renewals do not necessarily present the same qualities. The reconstructed buildings give a focused interest to the design of the interiors rather than the exterior envelope. When the indoors answer modernity needs, some of the façades remain unfinished, influencing as a result, the urban image of the Checkerboard, and the sustainability of the historical heritage of this period.

\section{GENERAL CONCLUSION}

The French checkerboard is a remarkable symbol concerning the transfer and the sharing of design qualities, concepts, 
and architectural perspectives. This research introduces an approach to understanding the colonial heritage and its perceptions in the Algerian society. The investigation of Biskra's historical center focuses on the classification of building conditions that occur to be decreasing through the years. The evaluation of the modification rate results and the modernization of the original French buildings is considered one of the main reasons behind the fading of its qualities. Some reckless actions and lack of awareness towards this heritage have an equal impact on the global image and harmony of the Ex-European city.

The French historical center's potentiality in Biskra today relies on the acknowledgment of the remaining qualities; in a way that serves the needs of the urban space and its users. The interaction and the connection between the ambiances of the built environment and the experiences it provides. It justifies the values of French monuments along to the importance of the perceptions conforming to the site's cultural journeys, which not only guides to the revalorization of the built heritage and its significance but equitably contributes to the raising of social consciousness and comprehending the legacy of the 19th and 20th centuries in Algeria.

\section{REFERENCES}

[1] J. A. Clapp, The City: A Dictionary of Quotable Thoughts on Cities and Urban Life. New Brunswick, New Jersey: Transaction Publishers, 2014.
[2] E. Yaldız, D. Aydın, and S. B. Sıramkaya, "Loss of city identities in the process of change: the city of Konya-Turkey," Procedia-Soc. Behav. Sci., vol. 140, pp. 221-233, 2014.

[3] A. Versaci, "The evolution of urban heritage concept in France, between conservation and rehabilitation programs," Procedia-Soc. Behav. Sci., vol. 225, pp. 3-14, 2016.

[4] F. Fatiguso, M. De Finoa, E. Cantatorea, and V. Caponioa, "Resilience of historic built environments: inherent qualities and potential strategies," Proced. Eng., vol. 180, pp. 1024-1033, 2017.

[5] P. Pizzaferri, Biskra, Queen of the Ziban and the South of Constantine, vol. 1-2. France: Jaques Gandinis Edition (in French), 2011.

[6] H. Barbara and T. Molnár, "The French legacies in Algeria: the architecture of a shared identity, the case of the Kasbah, Algiers and the colonial check board, Biskra," in Conference Proceedings, the 6th International Academic Conference on Places and Technologies, Pécs, Hungary, May 9-10, 2019, 2019, pp. 244-252.

[7] H. Barbara and T. Molnár, "Towards understanding the colonial heritage in Algeria: The case of Sheridan villa," Pollack Period., vol. 14, no. 1, pp. 223-234, 2019.

[8] M. Côte, The City and the Desert: The Algerian Low-Sahara. Paris: Karthala (in French), 2005.

[9] L. Sriti, A. Belakehal, K. Boussora, and A. Z. Saouli, "The colonial check board of Biskra where the history of the marginalization of a city center," Courrier du Savoir, no. 2, pp. 53-59 (in French), 2002.

[10] K. Kovás-Andor, "The architectural renewal of the main square of Kecskemét and its surrounding areas," Pollack Period., vol. 9, no. 3, pp. 119-126, 2014. 